demonstrates that doctors' behaviour can be changed by the use of data on their prescribing activities. The only intervention between September and December was a presentation of September's results to the clinical staff. Whether this will be sustained or not will be the subject of another audit.

\section{John Peters,}

Littlepace Medical Centre, Dublin 15, Ireland. regarding the influence of patient payment on antibiotic prescribing in Irish general practice. The Republic of Ireland is one of three European countries in which antibiotic use in general practice is increasing. ${ }^{1}$ Eligibility for Ireland's primary care services is determined by a means test with General Medical Service (GMS) card holders having access to GP services and medications free of charge. The remainder are private patients who pay a fee to access GP services.

We retrospectively reviewed a 2-week period in September 2011 in a practice with predominantly children and young patients presenting with symptoms that indicated a probable RTI (as in the Bradley et al study). The results were presented to the practice GPs and nurse in October and then a second 2-week period in December 2011 was then reviewed. Our results are shown in the table below.

The representation of GMS and private patients in September and December was approximately equal. Our findings show that there were more RTI presentations in December with less antibiotic prescribing overall, fewer antibiotics were prescribed to private patients in December, and higher use of delayed antibiotic prescribing.

As stated in many articles including the Bradley study, there are many external nonclinical factors that influence GPs prescribing such as patient's expectations, time constraints, patient volume, and mode of renumeration. 1,2,3,4 Our brief audit

\section{Table. Comparison of consultations for September and December 2011}

Parameter measured September December \% RTI presentations of $\quad 22.7 \quad 35.8$ total consults $\begin{array}{lll}\% \text { antibiotics given for RTI } \quad 67.8 & 60.0\end{array}$ $\%$ delayed antibiotics $\quad 27.9 \quad 37.2$ given for RTI \begin{tabular}{lll} 
\% GMS did get antibiotics & 53.2 & 57.6 \\
\hline
\end{tabular} \% PP did get antibiotics $83.7 \quad 62.5$ GMS = public patients. $P P=$ private patients .

\section{Claire Young,}

Littlepace Medical Centre, Dublin 15, Ireland. E-mail: iclaireyounglayahoo.ca

\section{Tom O'Dowd,}

Public Health and Primary Care, School of Medicine, Trinity College Dublin, Ireland.

\section{REFERENCES}

1. Murphy M, Byrne S, Bradley CP. Influence of patient payment on antibiotic prescribing in Irish general practice: a cohort study. Br J Gen Pract 2011; DOI: 10.3399/bjgp11X593820

2. Little P, Dorward M, Warner G, et al. Importance of patient pressure and perceived pressure and perceived medical need for investigations, referral, and prescribing in primary care: nested observational study. BMJ 2004; 328(7437): 444.

3. Coenen S, Michiels B, Renard D, et al. Antibiotic prescribing for acute cough: the effect of perceived patient demand. Br J Gen Pract 2006; 56(524): 183-190.

4. Geneau R, Lehoux P, Pineault R, Lamarche P. Understanding the work of general practitioners: a social science perspective on the context of medical decision making in primary care. BMC Fam Pract 2008; 9: 12

DOI: 10.3399/bjgp12X649007

\section{Situating general}

\section{practice training in the general practice context}

While I understand and agree with the longterm aim of increasing training time in the GP setting for GP trainees, I am unable to agree with some of the conclusions drawn by Goldie and Morrison. ${ }^{1}$

First, the training received in hospitals by GP trainees does not occur in isolation from the general practice setting. Within our vocational training scheme for example, during the time that our trainees are in their hospital placements our main focus is on putting their experiences into the general practice context. Furthermore, in our local deanery, all trainees do 6 months in GP practices prior to their final ST3 year, and this means that members of each small group are grounded with the perspective of the world they are preparing to enter. The socialisation and cohesiveness of the STs within their small group of GP trainees seems much more important than the more transient bonds formed while on hospital placements.

Second, obstetrics aside, I am sure that there is benefit to be gained by training in many hospital jobs as it allows the building of more specialist knowledge in commonly encountered general practice problems, for instance in sexual health, ENT, or dermatology. This knowledge is subsequently disseminated through peer learning to other members of their vocational training scheme small group and to the practices they work in later.

Finally, quality assurance of hospital posts means that the hospital leads for all our jobs are visited on a rolling cycle. We discuss with our hospital colleagues how our trainees can make the most of their time in hospital training experiencing, for instance, following a patient through a primary to secondary to primary care journey, understanding what makes a good referral from the hospital point of view, and viewing the primary care interface from the secondary care perspective. Given that commissioning is likely to lead to a more focused examination of the grey area between what can be done in primary or secondary care, fully understanding the boundary from all sides is likely to put us in a much stronger position to be able to manage it to the profession's best advantage.

Leaving aside the economic and logistical arguments of how to base training fully in primary care, arranging service provision in hospitals, or longer training in general practice, I strongly support extended training for GP STs within a primary care setting. I would, however, anticipate that an extra training year in the GP setting after completion of MRGCP would alleviate many of the concerns raised.

Tom Pelly,

Training Programme Director, Bristol Vocational Training Scheme, Severn Deanery, Horfield Health Centre, Lockleaze Road, Bristol, BS7 9RR.

E-mail: tompellyadoctors.org.uk 


\section{REFERENCE}

1. Goldie J, Morrison J. Situating general practice training in the general practice context. $\mathrm{Br} J \mathrm{Gen}$ Pract 2012; DOI: 10.3399/bjgp12X636245.

\section{GP training}

As a trainers group that meet regularly to discuss issues with GP training in Shropshire we have spent much time recently discussing the suitability of the trainees entering vocational training (VTS). First, we have had some concerns over the standard of the undergraduate teaching from certain universities (sometimes even in the EU) where basic examination techniques and medical knowledge have not been thoroughly taught. Can we as GP trainers really be expected to cover the whole MRCGP curriculum, language, and communication issues as well as teaching all basic examination skills and medical knowledge in the 2-3 hours teaching we have each week? These problems may be avoided by a more detailed look at the candidate's undergraduate experience before allowing them onto the VTS. Perhaps for those deemed to have potential, a preparatory clinical period could be arranged before joining the usual 3-year scheme.

Second, we have found that some trainees do not possess the necessary communication and interpersonal skills to pass the CSA part of the nMRCGP. It has been shown that, statistically, certain groups of doctors are more likely than others to repeatedly fail the CSA, as we have witnessed locally. A trainee who has grown up in the UK must be at an advantage in understanding and using not only the words of language but also the colloquialisms and nuances of speech as well as broader cultural aspects. We understand that the UK does rely heavily on taking doctors from overseas to fill the gap in posts nationally, however, if the UK continues to award training places to doctors who may later struggle (despite their best efforts) we feel it would only be fair to offer increased support with language and communication skills when they are accepted by the NHS or at the latest when they start their specialist training. However, some of us doubt if this can easily be 'taught'. We wonder if the situation is similar over the rest of the country.

The selection process already seems to have altered locally as the West Midlands Deanery did not fill all its vacancies on the GP training scheme in 2011 to avoid taking doctors who were unlikely to succeed. However, we would invite further discussion regarding these issues as we feel at present some of the trainees may have been treated unfairly. The consequences for them as individuals will be life long as they will be unable to work in general practice or retrain for any other speciality.

Drs Robert Richards, Paul Gardner, Charlotte Hart, Karen Robinson, Laurie Davies, Mike Arthur, Peter Bottomley, Richard Thompson, Julia Visick, and Sheelin Newton,

Ellesmere Medical Practice, Ellesmere, Shropshire. E-mail: emplanhs.net

DOI: 10.3399/bjgp12X649025

\section{Patience is always a virtue}

I recently worked in my local general practice during my medical school holidays. The phlebotomist was due to take sick leave and I was asked if I would cover a few of the sessions. During my clinical training in hospital I had taken many blood samples and although slightly hesitant, agreed.

My first day went well: the patients were keen to talk to me about my training and my confidence improved. I called my last patient, a lady in her mid-50s with epilepsy and learning difficulties who was attending with her carer. Her carer noted that it may be a difficult task (the last two attempts to take her blood had been unsuccessful). I noted that she was on carbamazepine and her blood levels had not been checked for some time. The patient had capacity and understood the need to have her blood taken, but refused every time I tried. Repeated sugar bribes from her carer and encouragement from both of us was to no avail.

After 30 minutes I reassured her again and explained it really wouldn't be too painful. She then calmly held out her arm and with continued reassurance from myself let me take a blood sample. Upon reflection I needed the half an hour talking with her to gain her trust. During this time learnt a lot about communicating with patients with learning difficulties and the value of patience in addressing their emotional needs. ${ }^{1}$ The role of GPs in addressing these needs and the skills required are key. A 30-minute consultation slot may be worth many 10 minute slots. Indeed, in this time I learnt valuable skills that will be useful, whatever area of medicine I choose.

Imogen Bone,

4th Year Medical Student, Brighton and

Sussex Medical School, Flat B, 8

Windlesham Gardens, Brighton, BN1 3AJ.

E-mail: I.Bone1@uni.bsms.ac.uk

\section{REFERENCE}

1. Aspray TJ, Francis RM, Tyrer SP, Quilliam SJ.

Patients with learning disability in the community. BMJ 1999; 318(7182): 476-477.

DOI: 10.3399/bjgp12X649034

\section{Out-of-hours primary care}

John O'Malley's interesting editorial' raises many good points and will, I hope, widen discussion about the entire provision of outof-hours $(\mathrm{OOH})$ care. I believe that the government in 2004 gave away too much in reducing the 24 -hour commitment at a time when locally organised cooperatives were already providing excellent care in many areas, tailored to the needs of those areas and not a national blueprint. I write as a former principal in practice for nearly 30 years and one now working limited sessions in $\mathrm{OOH}$.

$\mathrm{OOH}$ needs to be seen as a distinct subspeciality of primary care requiring tailored training and appraisal programmes. This is of special importance at the outset of revalidation. 'Audit' (now an old fashioned wordl is not really possible when the outcome of consultations and referrals is not available to the $\mathrm{OOH}$ doctor.

\section{Warren Luke,}

FRCGP, Ardgowan, 11 Learmonth Street, Falkirk, Stirlingshire, FK1 5AG. E-mail: warren.lukelasky.com

Member of the Faculty Board, West of Scotland Faculty RCGP. Sessional $\mathrm{OOH}$ doctor Forth Valley Health Board (these views are mine and not necessarily those of the above bodies). 